\title{
Leveraging the Laboratory Response Network: A Step Toward Implementing IHR (2005)
}

\author{
Tyler Wolford*, Christopher Chadwick and Chris Mangal \\ Public Health Preparedness and Response, Association of Public Health Laboratories, Silver Spring, MD, USA
}

\section{Objective}

To promote the Laboratory Response Network (LRN) as a model that supports global health initiatives, strengthens worldwide laboratory systems, and advances international partnerships to prepare for and respond to infectious disease threats.

\section{Introduction}

In 1969, the Twenty-Second World Health Assembly revised and consolidated the International Sanitary Regulations into what is known today as the International Health Regulations (IHR). The IHR promote a global collaboration to prepare for, respond to, and prevent the spread of infectious disease and other public health threats. In 2005, the IHR was once again reviewed and expanded to address the increasing threat of emerging infectious disease due to globalization and urbanization. 195 State Parties agreed to adopt and implement IHR (2005); however, as of May 2013, over 100 of these States still had not yet met the eight core capacities outlined in the IHR (2005). In February 2014, the Obama administration launched the Global Health Security Agenda with the aim of moving toward a world safe and secure from infectious disease threats. The Global Health Security Agenda offers a path forward to support countries in achieving the core capacities of the IHR. APHL proposes leveraging the distributed structure of the US managed Laboratory Response Network for Biological Threats Preparedness (LRN-B) to develop the core capacity of laboratory testing and to fulfill the laboratory strengthening component of the Global Health Security Agenda. The LRN supports five of the eight core capacities and could serve as a model for State Parties lacking resources and an implementation plan. The LRN, founded in 1999 by Centers for Disease Control and Prevention (CDC), Federal Bureau of Investigation (FBI) and the Association of Public Health Laboratories (APHL), is a specialized network of laboratories that are capable of an all-hazard response to a variety public health threats. Leveraging LRN assets internationally would provide a standardized approach toward IHR (2005) implementation and ensure a global collaboration to defend against public health threats.

\section{Methods}

We performed a literature review to determine if the mission, vision, infrastructure, and success of the LRN was a biosafety and biosecurity asset for implementation of IHR (2005) in struggling regions.

\section{Results}

The vision of the LRN for preparedness and response to biological, chemical, radiological and other public health threats aligns with the objectives outlined in the IHR (2005) and supports five of the eight core requirements. Although a plan will need to be further developed in order the meet the remaining three core capacities, the LRN model will provide a strong base for building an implementation plan that supports an all-hazards response to public health threats internationally.

\section{Conclusions}

Implementation of the IHR (2005) is a complex process, especially for State Parties lacking adequate resources and management. The infrastructure of the LRN can be leveraged to assist with meeting the core capacities outlined in the regulations. The LRN model will ensure a standardized approach towards implementation, promote international communication, and provide a link for a connected global response to infectious disease.

\section{Keywords}

Laboratory Response Network; International Health Regulations; LRN; Global Health Security Agenda

\section{References}

1. World Health Organization, World Health Assembly. International Health Regulations (2005). 2nd ed. Geneva: The Organization; 2008.

2. GlobalHealth.Gov. [Internet] Washington, DC: Global Health Security Agenda: Toward a World Safe \& Secure from Infectious Disease Threats. [cited 2014 August 1] Available from: http:// www.globalhealth.gov/global-health-topics/global-health-security/ ghsagenda.html.

3. Centers for Disease Control and Prevention [Internet]. Atlanta, GA: The Laboratory Response Network Partners in Preparedness. May 2013 [cited 2014 August 1] Available from: http://www.bt.cdc.gov/lrn/.

\footnotetext{
*Tyler Wolford

E-mail: tyler.wolford@aphl.org
} 